\title{
A Web-based Portal for Ornamental Plants and Flowers in Arusha City, Tanzania
}

\author{
Kenneth Patrick Asiimwe \\ The Nelson Mandela African Institution of Science and Technology, P. O. Box 447, Arusha, Tanzania \\ E-mail: patricka@nm-aist.ac.tz, kasiimwe93@gmail.com \\ Dina Machuve and Mussa Ally Dida \\ The Nelson Mandela African Institution of Science and Technology, P. O. Box 447, Arusha, Tanzania \\ E-mail: dina.machuve@nm-aist.ac.tz,mussa.ally@nm-aist.ac.tz
}

Received: 07 September 2019; Accepted: 15 October 2019; Published: 08 April 2020

\begin{abstract}
There is a wide collection of invaluable varieties of ornamental plants and flowers available for sale by vendors in Arusha city contributing to local employment, and food security. Horticulture in Tanzania is dominated by small scale farmers in Arusha that contribute to about $70 \%$ of the produces in the sector. However, there are challenges that need to be addressed including; inadequate information for the development of the sector and livelihoods of the vendors. The information on the varied species of ornamental plants and flowers are mainly undocumented and not digitized. This limits access to the scientific community and the general public bringing on these varieties in Arusha a growing conservation concern. The other challenge is that the small-scale vendors have limited visibility to regional markets and international market places which hinders their business growth. On this study, a Web portal was developed for inventory, mapping and digitization of the various species of ornamental plants and flowers as a solution to above challenges. Data collection was conducted using various data collection techniques such as; Interviews, observations, Questionnaire (Open Data Kit) and re-viewing numerous research papers in seven wards of Arusha city where the vendors grow and sell a number of species of ornamental plants and flowers. Both qualitative and quantitative methods mentioned above were deployed to provide insights on the ornamental plants and flower business operations. For the survey, 70 varieties of ornamental plants and flowers were gathered and arranged categorically in terms of taxonomy and usage and uploaded on the portal. The portal developed indicates the potential to help stakeholders find plants' and flowers' varieties information, images, and sales location online, the vendors will be able to advertise their products on the portal and conduct business with customers online. In addition, it will also help Arusha City Representatives with baseline information on the sector to make informed plans and decisions.
\end{abstract}

Index Terms - Web Portal, Ornamental Plants and Flowers, Web-based System, Vendors, Inventory, Diversity.

\section{INTRODUCTION}

Horticulture is a significantly huge investment and dynamic industry which deals with thousands of species and variety of ornamental plants and flowers. Europe is the leading producer of ornamentals with the biggest market share occupied by the Netherlands (35\%), Italy (18\%) and Germany (11\%). In Africa, ornamental production has improved in the past decade with Kenya ranking first, followed by Tanzania, South Africa and Uganda respectively [1].

This is attributed to the adoption of ICT and technology in the ornamental sector in Africa [2]. For example, greenhouse technology, fertigation systems, innovative forms of water treatment and recirculation techniques, modern acclimatization and heating technologies, and applied highly sustainable crop protection methods to reduce environmental hazards have been integrated in the horticulture sector creating remarkable diversity in the horticulture sector [3].

However, the adoption of ICT in horticultural production is still a challenge [4].

Horticulture in Tanzania has for several years been a backbone of growth and development with an estimated annual growth rate between $6 \%$ and $10 \%$ per annum [5], contributing to about a quarter of the GDP. The sector also employs nearly three quarters of all Tanzanian workers contributing to local employment and food security [6]. The horticulture sector is dominated mainly by smallscale farmers (vendors) in Arusha City selling ornamental plants and flowers mostly on road sides (streets). The small-scale farmers contribute about $70 \%$ of the produces in the sector and also cannot export their produce since they are not connected to regional and international market [7].

However, horticulture particularly in Tanzania is challenged with inadequate access to information by stakeholders that include researchers and buyers. Also, there is lack of awareness by stakeholders with in Tanzania and internationally about economic and social potential of horticulture sector [8]. There lacks access to information 
on varying species of ornamental plants and flowers in Tanzania [9].

The information on plants and flowers is not only a contribution to the cultural heritage of any country like Tanzania but also of significance for scientific and practical interest [10].

Conservation of the various species of ornamental plants and flowers relies heavily on official statistics, but since the information is not digitized and undocumented, much is absent on the official statistics bringing about a growing conservation concern [11].

The ornamental plants and flowers contribute to reduction of carbon foot print [12].

Therefore, this study aims to find solutions to challenges such as; inadequate information on the variety species of ornamental plants and flowers in Arusha City (mainly undocumented and not digitized) and also the limited visibility of the vendors in the regional and international market through developing a web based portal for inventory, mapping and digitization of ornamental plants and flowers in Arusha City. Both qualitative and quantitative methods such as Interviews, observations, website search, Questionnaire (Open Data Kit) and reviewing numerous research papers were deployed to provide insights on the ornamental plants and flower business operations. The developed web portal will be freely accessible online that will not only provide profile information of horticulture, information (Taxonomy) on the variety species of ornamental plants and flowers sold by vendors in Arusha City but also act as a marketing tool in order to connect the vendors to regional and international markets.

\section{RELATED WORKS}

A study by [13] sought to develop an inventory and botanical identity of seasonal flowering plants grown in home gardens in the District of Nainital, Uttarakhand. From the survey that was carried out from 2013 to 2015 , a list of 150 seasonal flowering plants with 120 genera belonging to 50 families were collected, recorded with their botanical names, vernacular names, trade names, family, native, nature, season with appropriate remarks of variation in shape and color, method of propagation with economic status and photographs. The study also came up with a statistical summary of the number, percentage of families, genera, and species.

The study however, did not provide an online avenue through which these seasonal flowering plants can be accessed any time by various researchers. Therefore, this study was aimed to develop a web portal providing an online avenue through which the various species of ornamental plants and flowers can be accessed freely any time by various researchers.

A study by [14] was aimed at coming up with a Floristic inventory of vascular plants mainly in Nam $\mathrm{Ba} \mathrm{Na}-$ tional Biodiversity conservation area of the Lao people's Democratic Republic. From the joint field study that was conveyed by the Korean and Lao's experts in the year of 2015 to 2017, it was recorded that there were 33 species of ornamental plants among others, species that are edible plants, species that are economic plants, families and genera distributed in the Nam Ha National Biodiversity conservation area. The study provided scientific names, families and genera of the vascular species.

However, the study did not provide conservation status of the vascular plants and also did not provide vernacular names, trade names, native places, images, and description of the vascular plants by color, shape, size, and method of propagation, economic status of the ornamental plants. More so, the inventory does not provide visualization of the data collected on the vascular plants. The study aimed to develop a web portal through which the above information will be provided.

The Antipoison Center and Pharmacovigilance of Morocco (ACPM) produced a report with a concern on poisoning caused by plants. This sparked off the study [15] which aimed to come up with an inventory of toxic plants in Morocco that would enable the necessary study on their nature and monographs. This was aimed to separate the good plants such as the ornamental plants from the toxic ones since it was found out that some plants are toxic and cause various disorders in both human beings and animals. The Antipoison Center and Pharmacovigilance of Morocco (ACPM) required this study so as to sound an alarm on these poisonous plants in the country. The study came up with a list of the most toxic plants in Morocco and provided them with the French name, vernacular name (Moroccan), family name to which these toxic plants belong to.

However, the study did not provide the native places, genus, and descriptions by size, color, shape, images of the toxic plants, economic status (prices) of the sold plants, and visualization of the data collected on the toxic plants. Additionally, the inventory does not provide visualization of the toxic plants. The study was aimed to develop a web portal that will avail the above information and visualization for the ornamental plants and flowers in Arusha City.

The study by [16] was aimed at addressing the urgent problem which was identified as inventory with bio ecological assessment of vital state and growth conditions of ornamental arboreal plants regarded as the main structural elements landscape composition. One of the objectives of the study was to form the collection of the ornamental and other valuable plants economically such that they could be analyzed to reveal their characteristics so as to select them and propagate the most perspective plant species. Fortunately for Nikita Botanical gardens, a rich collection of these plants were created due to the work of generation of researchers. The inventory provides bio ecological assessment of dendrological collection (trees, shrubs, and lianas) thus, trees $(42.2 \%)$, polubushes $(1.5 \%)$, bamboos $(0.7 \%)$, liana $(8.2 \%)$, bushes $(47.4 \%)$.

However, the inventory does not provide trade names, vernacular names, families, genus of the ornamental arboreal plants. Additionally, the inventory does not provide visualization of the ornamental plants. This study was aimed to develop a web portal through which the above information will be freely accessible online. 
Therefore, the proposed system will therefore provide the botanical identity, including; English name, Scientific name, genus, family, native, vernacular name (Swahili), description, images, propagation period, location of the ornamental plants and, uses in terms of (Medicinal/Herbal, Edible/Food, Poisonous and Ornamental), Conservation in terms of quantity (Extinct in the wild, Extinct, Critically Endangered, Endangered, Least Concern Vulnerable, Nearly Threatened, Data Deficient and Not Evaluated) and also provide a visualization tool for the users from which conservation plans can be based and also provide a marketing platform for the vendors in Arusha City.

Furthermore, there are existing systems used in Tanzania by TPRI (Tropical Pesticides Research Institute) such as; TanBIF (Tanzania Biodiversity Information Facility) considered digitalizing local Institutions biodiversity collections of which it did not finish its objective and additionally, its yet to be online and BRAHMS (Botanical Research and Herbarium Management System) database management system for botanical herbaria and researchers, with comprehensive and advanced features to manage, assemble, analyze publish and edit botanical data. However, it uses DOS (Disk Operating System) which is not easily understood by an ordinary user since it does not have a GUI (Graphical User Interface) like windows, DOS is an out dated and obsolete operating system. Additionally, version 8 is not free as it requires license. The web portal developed will run on all modern operating systems and will be availed free of charge. It is also easy to use with user-friendly interfaces to be used for inventory, mapping and digitization of ornamental plants and flowers.

\section{Methodology}

The research was conducted in Tanzania specifically in areas of Arusha City (see Fig. 1) where the horticultural sector activities are concentrated [17]. Arusha is a region that is located in the North and to the East of Kilimanjaro and Tanga. It also shares a boarder in the South with Dodoma and in the West Singida, Mara and Shinyanga regions. Arusha is strategically located with good geographic conditions, good climate suitable for growth of ornamental plants and flowers and thus many vendors carry out their businesses in these areas [18].

Table 1. Evolutionary Prototyping methodology versus other software development methodology. [20]

\begin{tabular}{c|ccc}
\hline Methodology & Flexibility & $\begin{array}{c}\text { Client } \\
\text { Interaction }\end{array}$ & $\begin{array}{c}\text { Phase containment } \\
\text { of error }\end{array}$ \\
\hline Waterfall & No & One time & Low \\
Evolutionary & Few & Some time & Low \\
Spiral & Fully & Frequent & High \\
\hline
\end{tabular}

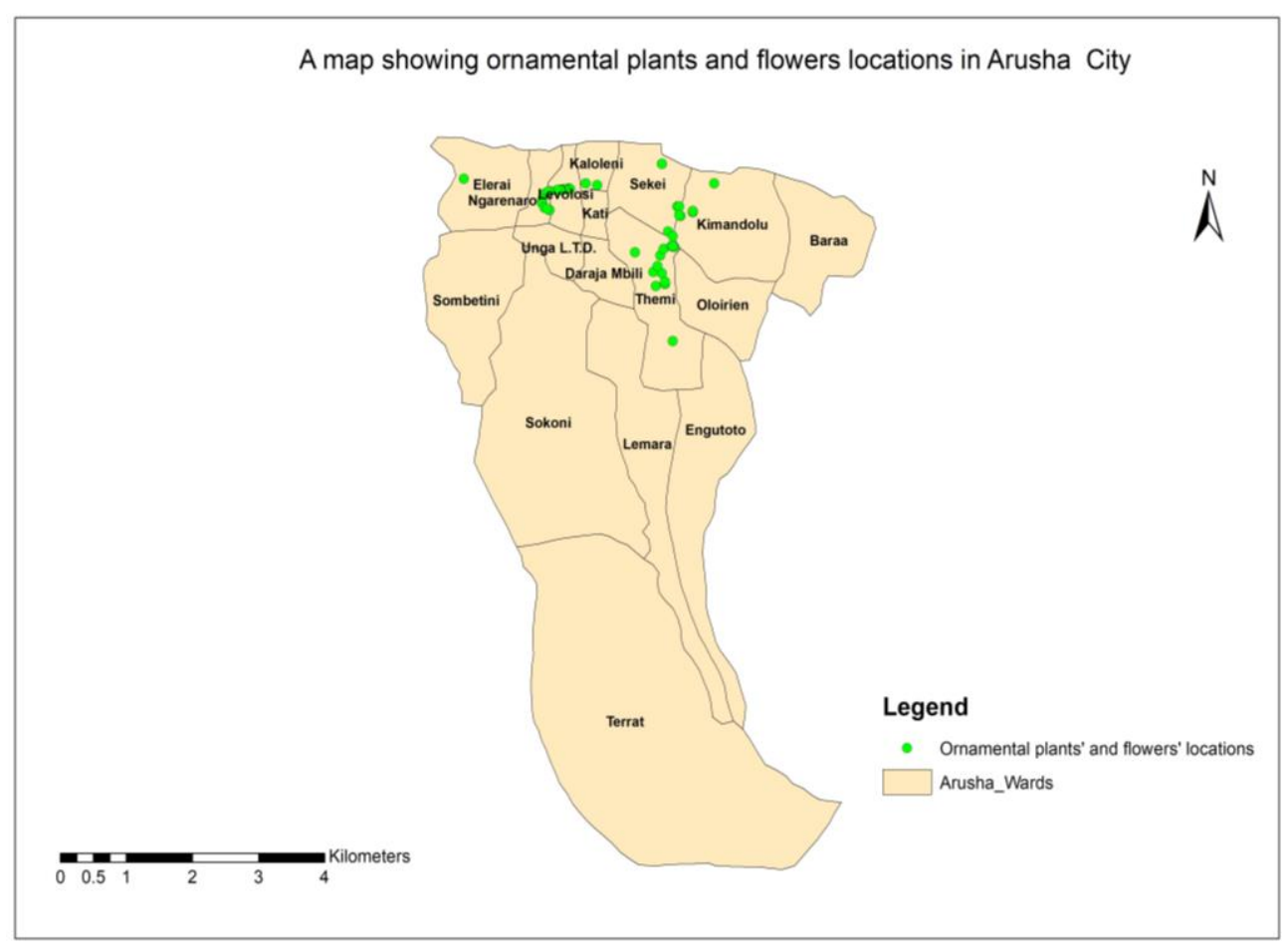

Fig.1. Map of Arusha mapping location of ornamental plants and flowers.

A simple random sampling technique was used and, for the study, each respondent was chosen solely by coincidental and everybody was given equivalent chance of participation. From the study, quantitative and qualitative data were collected using data collection techniques such as; Interviews, observations, website search, Question- naire (Open Data Kit) and reviewing numerous research papers and later analyzed using python library known as pandas. Evolutionary prototyping methodology was selected and used to develop the web portal since it allows for user involvement throughout the system development duration leading to user requirement satisfaction and also 
chosen simply because, implementation is commenced when the requirements are best understood unlike rapid prototyping where the implementation starts with the least understood requirements. Table 1 below compares Evolutionary prototyping with other development methodologies [19].

\section{A. Proposed System (Ornamental Web portal)}

The proposed study results showed that, vendors are enthusiastic to use different methods to be able to access the web portal and use it to market their products (see Fig. 3) and also for the botanists and other types of users like Arusha City representative and researchers to access the botanical identity or information of the ornamental plants and flowers together with vernacular names (Swahili), Family, native, description, images, genus, propagation period, uses in terms of (Medicinal/Herbal, Edible/Food, Poisonous and Ornamental), Conservation in terms of quantity (Extinct in the wild, Extinct, Critically Endangered, Endangered, Least Concern Vulnerable, Nearly Threatened, Data Deficient and Not Evaluated), and vendors details selling the ornamental plants and flowers by location which will allow their clients to contact them, phone number and ward where they grow the ornamental plants and flowers.

We hence suggested a solution that comprises of a Web Based System. Users of the proposed system are divided into two batches including; the first includes Researchers, Botanists who interact with the system and the second includes administration (System Administrator) who uses ornamental web portal to perform administrative activities working together with the central database (see Fig. 6).

The reason as to why we chose Web technology is because the number of internet users in Tanzania is increasing and according to TCRA (Tanzania Communication Regulatory Authority), rose by $16 \%$ in 2017 to 23 million [21]. Additionally, based on data collection results that were acquired showed that $58.3 \%$ of the vendors said they can afford internet and have access to smart phones, more than $41.7 \%$ that have no access to smart phones as shown in Fig. 2. Therefore, developing a Web based portal guarantees maximum user coverage and also it easy to use by the users.

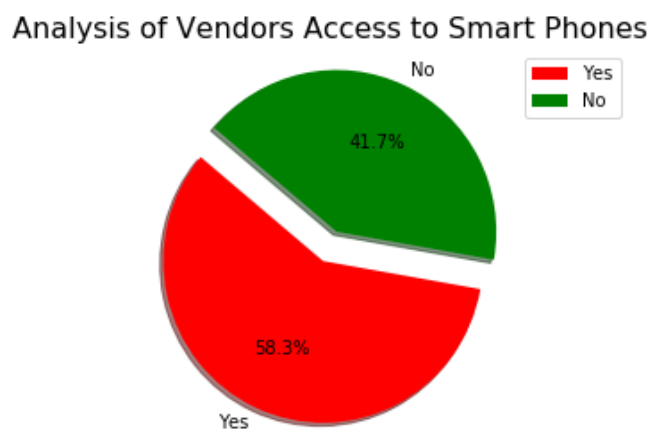

Fig.2. vendor's access to smart phones

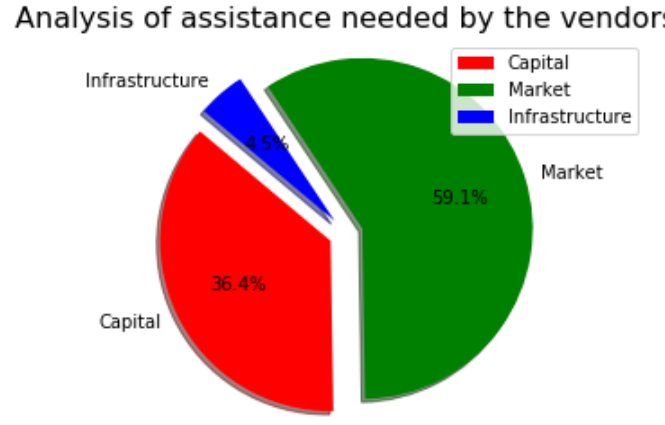

Fig.3. vendor's assistance they need

Additionally, the saturation of internet has been quickly increasing in the last 6 years in Tanzania, growing from $17 \%$ to $45 \%$ in 2012 and 2017 respectively. More so, the number of people using the internet has been also rising from 7.52 to 23 million in 2012 and 2017 respectively and they are mostly residing in urban centres [22].

\section{B. Requirements analysis}

Both functional and non-functional requirements specifications were measured in developing the Ornamental Web portal. Functional requirements describe the exact function the system has to do such as authentication of users, allow registration to mention a few. Whereas, nonfunctional requirements define values which the system shall have for example; usability, scalability to mention a few [23]. The tables below shows functional (Table 2) and non-functional (Table 3) requirements of the Ornamental Web portal respectively.

Table 2. Functional Requirements

\begin{tabular}{|c|c|}
\hline Requirement & Description \\
\hline $\begin{array}{l}\text { Registration } \\
\text { (Users, Ven- } \\
\text { dors) }\end{array}$ & $\begin{array}{l}\text { Web portal shall allow registration and login for } \\
\text { access of exceptional information and guidance } \\
\text { customized for a specific type of users, the ad- } \\
\text { ministrator will register vendors and also ven- } \\
\text { dors can register and await approval from an } \\
\text { administrator, same applies to all new users }\end{array}$ \\
\hline $\begin{array}{l}\text { Manage user } \\
\text { Accounts }\end{array}$ & $\begin{array}{l}\text { The administrator shall Add, delete users and } \\
\text { vendors. }\end{array}$ \\
\hline $\begin{array}{l}\text { Add ornamen- } \\
\text { tals (upload } \\
\text { images), delete }\end{array}$ & $\begin{array}{l}\text { The administrator shall be able to upload images } \\
\text { of the ornamentals and add information of } \\
\text { ornamental plants and flowers }\end{array}$ \\
\hline Search & $\begin{array}{l}\text { Users and Administrator shall have an advanced } \\
\text { search option to ease on information retrieval }\end{array}$ \\
\hline $\begin{array}{l}\text { View orna- } \\
\text { mentals }\end{array}$ & $\begin{array}{l}\text { A system shall be able to display the } \\
\text { information of ornamental plants and flowers. }\end{array}$ \\
\hline Visual Data & $\begin{array}{l}\text { The administrator shall be able to upload a CSV } \\
\text { file in the database for visualization, users should } \\
\text { be able to select entries and perform } \\
\text { visualization. }\end{array}$ \\
\hline Chat & $\begin{array}{l}\text { The system shall provide access to chat rooms } \\
\text { for vendors, botanists and other users, store } \\
\text { messages in chatrooms, display messages in } \\
\text { group chatrooms }\end{array}$ \\
\hline
\end{tabular}


Table 3. Non Functional Requirements

\begin{tabular}{|c|l|}
\hline Requirement & \multicolumn{1}{c|}{ Description } \\
\hline Performance & $\begin{array}{l}\text { A system shall be able to process user queries } \\
\text { in a shortest time possible, Bringing up-to-date } \\
\text { and saving records shall be fast Login, logout } \\
\text { process shall be done quickly }\end{array}$ \\
\hline Security & $\begin{array}{l}\text { A system shall enable authentication of users } \\
\text { within an encrypted password, It should re- } \\
\text { member the password and username of the user }\end{array}$ \\
\hline Usability & $\begin{array}{l}\text { A system shall be user friendly so that it can be } \\
\text { easily used by all types of users }\end{array}$ \\
\hline Robustness & $\begin{array}{l}\text { Shall be able to recover from failure in case of } \\
\text { connection problems }\end{array}$ \\
\hline Availability & Shall be available when needed \\
\hline
\end{tabular}

\section{System Design}

Requirements analysis above in B contributed to the design of the system ornamental Web portal. It was from the requirements analysis that system design was achieved.

The Fig. 4 and Fig. 5 below are Use Case Diagrams presenting Actors and their associations with Use Cases. Use Case Diagrams represent the collaboration between users and the system. It defines type of activities a user can execute in a system. Actions are; Use Cases, and Users are; Actors. For the proposed system, ornamental Web portal, Actors are, User, Admin, and vendor. Use cases include; Login, Register for a new account, search for plant and flower info, view plants and flowers info, add comment, Logout, select categories for visualization, view advert, create advert, chat, add/delete plants and flower info, upload data for visualization, Approve advert, manage chat, view chat messages, view orders, delete order, add/delete/approve user and vendor account and place order.

\section{Database Design}

This comprises of documenting entities, their relation- ships, and entities' attributes. For the study, an Entity Relationship diagram was used to show the relationship of system's entities and their attributes from which a relational schema was extracted. An Entity Relationship Diagram is a technique used to denote entities and their relationships in database design. Entities include; User, Order, Plant, Flower, Vendor, Chat, Comment, Visual data and Advert.

Below are the relational schemas of the EntityRelationship ER Diagram

1) User(userID, DOB, name, gender, phone, occupation, email, password, role, location)

2) Order (SaleID, reference, item, quantity, total_amount, date_added, date_time, userID, status, v_id)

3) Plant(plant_id, english_name, family_name, vanacular_name, trade_name, botanical_name, image, propagation_period, description, native_name, order, genus, uses, quantity, v_id)

4) Flower(flower_id, english_name, family_name, vanacular_name, trade_name, botanical_name, image, propagation_period, description, native_name, order, genus, uses, quantity, v_id )

5) Vendor(v_id, v_name, v_gender, location, biz_status, dob, challenges, no_of_employees, edn_level, v_phone, start_year, v_email)

6) Chat(chatID, description, userID, reply, datePosted, timePosted, date_added, attachment)

7) Advert(id, image, description, v_id, status, price)

8) Comment(commentId, userID, subject, message, date_posted)

9) Visual data(id, gi_ward, gi_sex, gi_educ, gi_smartphone, plants_expensive, plants_exprice, flowers_fast, flowers_faexp, plants_fast, gi_facility, mktinfo_bizzassist)

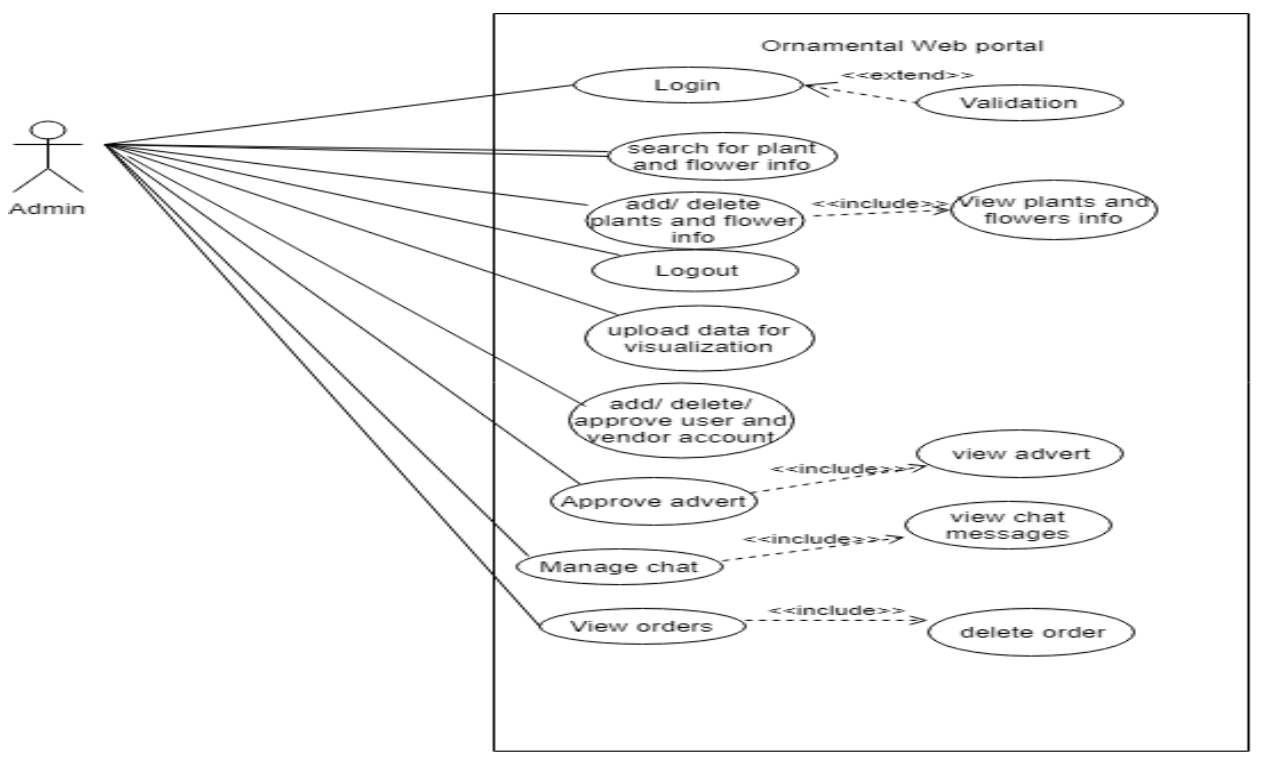

Fig.4. Use Case Diagram for the Proposed System showing user and vendor 


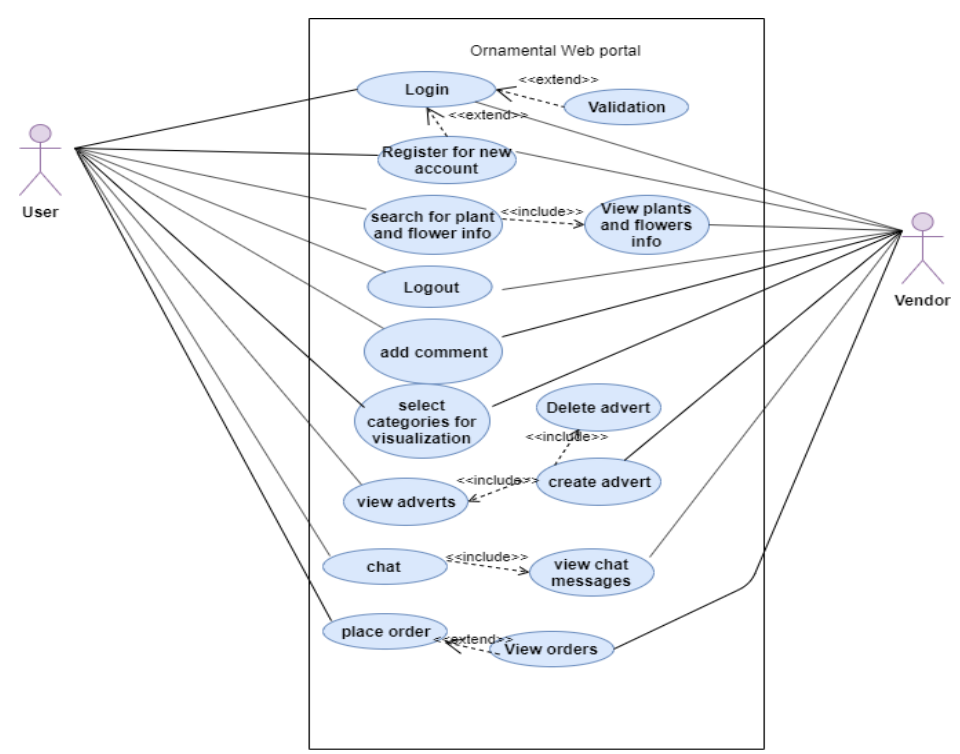

Fig.5. Use Case Diagram for the Proposed System showing user and vendor

\section{E. System development}

Selecting system development technologies for the proposed ornamental system depended on complexity, time, and cost of the technologies. That being said, all of the technologies used to develop the ornamental web portal or system are open source tools meaning the software's source code is publicly accessible and therefore anybody can use them free without incurring any cost [20].

\section{1) Database}

The ornamental web system database was developed using My Structured Query Language (MySQL). MySQL is compatible with various operating systems platforms like; i5/OS, BSDi, Symbian, OS/2 Warp, eComStation, IRIX, Microsoft Windows, OpenSolaris, Novell NetWare, Linux, SCO UnixWare, SunOS, AIX, Solaris, FreeBSD, Mac OS X, Tru64, HP-UX, and Sanos NetBSD QNX. From this therefore, MySQL was chosen in developing the systems' database with guarantee that the system will run in different Operating System platforms. MySQL was also chosen as a database management system because it is an open source, scalable and robust. MySQL is used for a varied variety of purposes, including e-commerce, logging applications and data warehousing. Additionally, the most common use of MySQL is for web-based applications.

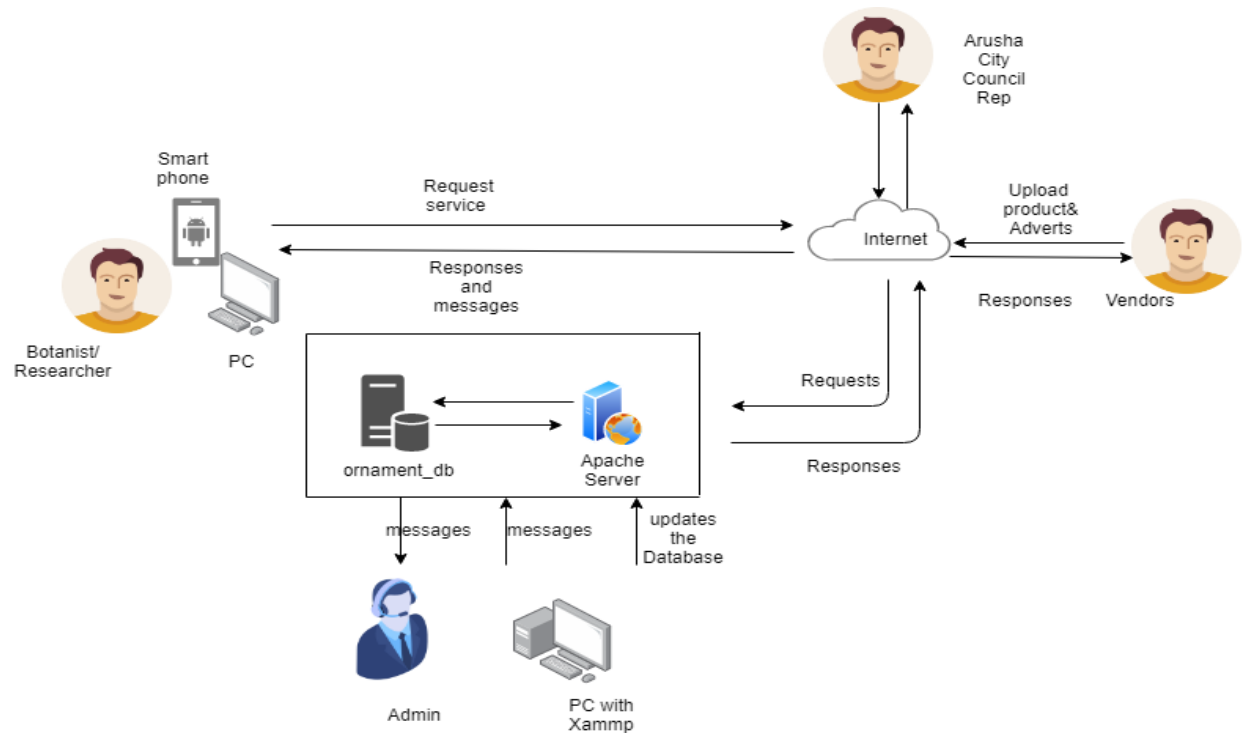

Fig.6. Conceptual framework of the proposed system 
Table 3. Client-Side Scripting Languages and Description

\begin{tabular}{|c|c|}
\hline Language & Description \\
\hline HTML & $\begin{array}{l}\text { HTML is basically for formatting and display- } \\
\text { ing data. It is the most frequently used lan- } \\
\text { guages to develop websites. HTML offers the } \\
\text { simple arrangement of sites, which is greater } \\
\text { and enhanced by other technologies like JavaS- } \\
\text { cript and CSS }\end{array}$ \\
\hline CSS & $\begin{array}{l}\text { CSS in full is Cascading Style Sheet. Particular- } \\
\text { ly directs on how the HTML elements of a } \\
\text { website should actually look at the user inter- } \\
\text { face page. CSS helps to style web content so it } \\
\text { appears to the user the way it was intended to be } \\
\text { seen }\end{array}$ \\
\hline BOOTSTRAP & $\begin{array}{l}\text { Used to capture data without hiding the web } \\
\text { page content. Consists of HTML and CSS form } \\
\text { templates, buttons, navigation, JavaScript exten- } \\
\text { sions and other interface design components }\end{array}$ \\
\hline JAVASCRIPT & $\begin{array}{l}\text { JavaScript was used to alter the website content } \\
\text { and style it to perform in different ways in re- } \\
\text { sponse to a user's activity, used in validation of } \\
\text { the system form's data inputs. }\end{array}$ \\
\hline $\begin{array}{l}\text { Angular } \\
\text { JavaScript }\end{array}$ & $\begin{array}{l}\text { Angular JavaScript library "angular.min.js" was } \\
\text { used to validate the form interfaces while the } \\
\text { user is typing }\end{array}$ \\
\hline AJAX & $\begin{array}{l}\text { AJAX was used to load the content of the web } \\
\text { pages such as chat room dynamically and auto- } \\
\text { matically refreshing in the background. }\end{array}$ \\
\hline $\begin{array}{c}\text { Canvas } \\
\text { JavaScript }\end{array}$ & $\begin{array}{l}\text { Canvas JavaScript was used for data visualiza- } \\
\text { tion where the file ("canvasjs.min.js"), a JavaS- } \\
\text { cript library for plotting graphs was used along- } \\
\text { side HTML and Hypertext Preprocessor (PHP) } \\
\text { to display content dynamically from the data- } \\
\text { base. }\end{array}$ \\
\hline
\end{tabular}

\section{2) Server-Side Technologies.}

These sever side languages are used in developing interactive websites which offer dynamic web contents of databases to users and the reverse is true. Presently, a lot of scripting languages are available for server-side such as; Nodes.js, Django, Ruby on Rails, PHP and Each server-side language has its benefits and drawbacks giving complications to programmers when it comes to selecting a right server-side technology for developing of a dynamic website applications [20]. For the case of this study, PHP was selected and used to develop the proposed system solution. Used to come up with the dynamic web system contents. And also among the furthermost used server-side scripting languages used in web-based systems implementation. Several web-based systems use PHP and thus makes it easy to get support and help of its developers worldwide.

Due to the PHP integration with the database and popularity among other languages, it was therefore used to implement the Ornamental Web portal. It was used in the the development of interfaces of the web portal. For example; (see Fig. 7). It is a plant and flower registration interface which allows the administrator to interact with
Web portal and be able to add information of ornamental plants and flower details: English name, Botanical name, Trade name, Family name, Native name, Vernacular name, Description, Propagation period, image, genus, upload image, genus, uses in terms of (Medicinal/Herbal, Edible/Food, Poisonous and Ornamental), Conservation in terms of quantity (Extinct in the wild, Extinct, Critically Endangered, Endangered, Least Concern Vulnerable, Nearly Threatened, Data Deficient and Not Evaluated).

Table 4. Comparing Server Side Scripting Technologies (source: [20])

\begin{tabular}{|c|c|c|c|}
\hline Language & $\begin{array}{c}\text { Ease of getting } \\
\text { started setting up } \\
\text { local environment }\end{array}$ & $\begin{array}{c}\text { Integration with } \\
\text { Database }\end{array}$ & $\begin{array}{l}\text { Populari- } \\
\text { ty }\end{array}$ \\
\hline PHP & $\begin{array}{l}\text { Simplest (requires } \\
\text { marginal work to } \\
\text { build a new PHP } \\
\text { file and view it on } \\
\text { the local server) }\end{array}$ & $\begin{array}{l}\text { Takes the greatest } \\
\text { support upon initial } \\
\text { setup as it incorpo- } \\
\text { rates easily with } \\
\text { Oracle, MongoDB } \\
\text { PostgreSQL, } \\
\text { MySQL, and upon } \\
\text { installation }\end{array}$ & $11.7 \%$ \\
\hline Django & $\begin{array}{l}\text { Complicated as } \\
\text { setting up the } \\
\text { initial hostname, } \\
\text { port number and } \\
\text { URL patterns, } \\
\text { produce addition- } \\
\text { al steps that can } \\
\text { be puzzling and } \\
\text { hard to compre- } \\
\text { hend }\end{array}$ & $\begin{array}{l}\text { Depends on driver's } \\
\text { support added in } \\
\text { Python language. } \\
\text { Supports most of the } \\
\text { database types how- } \\
\text { ever may not be } \\
\text { clear on how to } \\
\text { utilize and may be } \\
\text { hard to find. }\end{array}$ & $0.1 \%$ \\
\hline $\begin{array}{l}\text { Ruby on } \\
\text { Rails }\end{array}$ & $\begin{array}{l}\text { Although easy to } \\
\text { create a new } \\
\text { project and run on } \\
\text { a local server, it is } \\
\text { however difficult } \\
\text { to set up }\end{array}$ & $\begin{array}{c}\text { Receives database } \\
\text { support from Ru- } \\
\text { byGem packages } \\
\text { since support for } \\
\text { databases is not } \\
\text { available. }\end{array}$ & $0.3 \%$ \\
\hline Node.js & $\begin{array}{l}\text { Comprise of } \\
\text { extra challenging } \\
\text { syntax that may } \\
\text { not be fairly clear } \\
\text { to a beginner }\end{array}$ & $\begin{array}{l}\text { Does not have sup- } \\
\text { port upon initial } \\
\text { setup for any Data- } \\
\text { base, however, } \\
\text { depends/relies on } \\
\text { packages }\end{array}$ & $0.24 \%$ \\
\hline
\end{tabular}

And also allow the stakeholders to be able to register for example; vendors can register details: Vendor name, DOB (date of birth), phone, email, gender, password, occupation, location. After the account being approved by the Admin then the vendor can login and create adverts for his or her products (see Fig. 8) as well as viewing the oders as they are sent by their clients (see Fig. 9 shows a client can place an order by clicking on order button and will specify the quantity of the plant or flower and also calculate the price for the client and vendor from which business can be made). Additionally, they can engage in a public chat, add comments, and also perform visualization. 


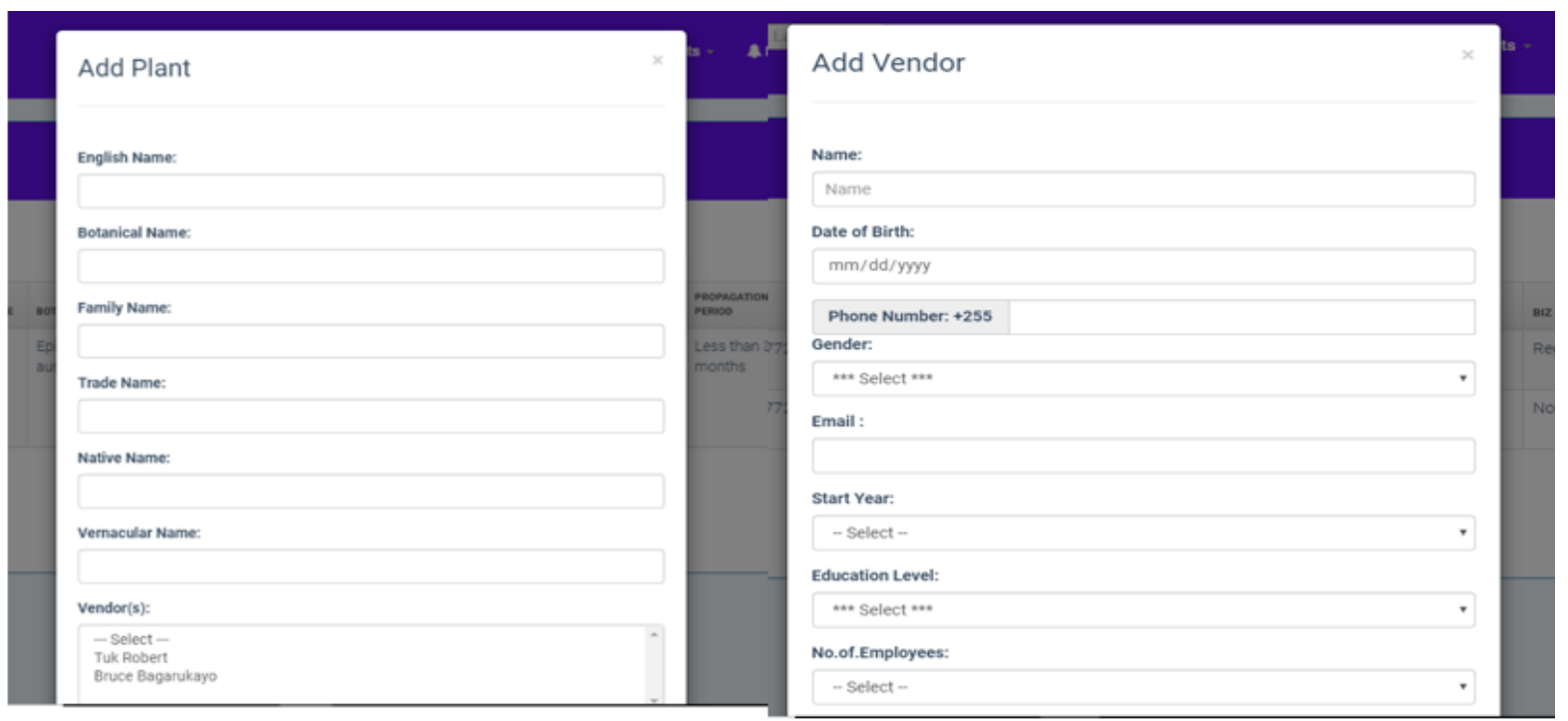

Fig.7. Web Page prototype Interface Showing Registration of Plant Details and vendor registration

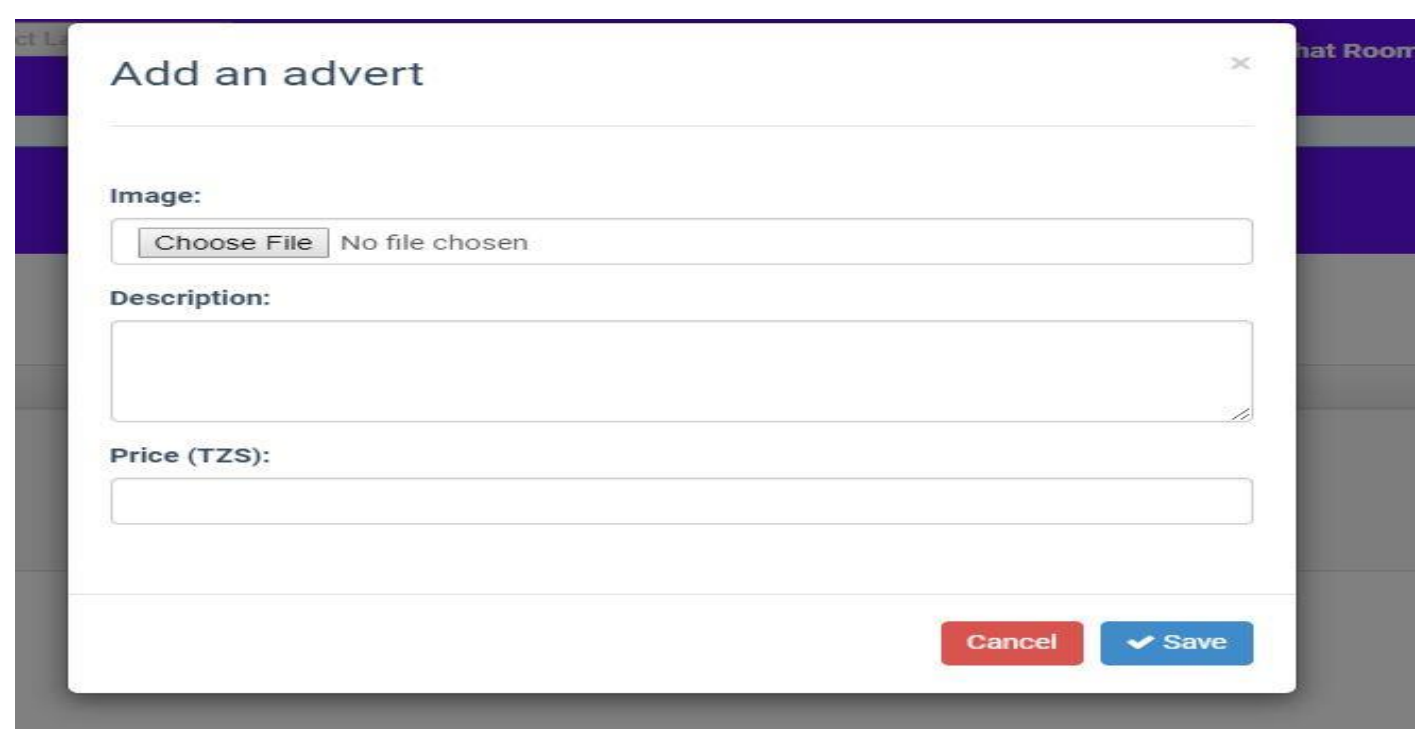

Fig.8. Web Page prototype Interface Showing how vendor can create advert

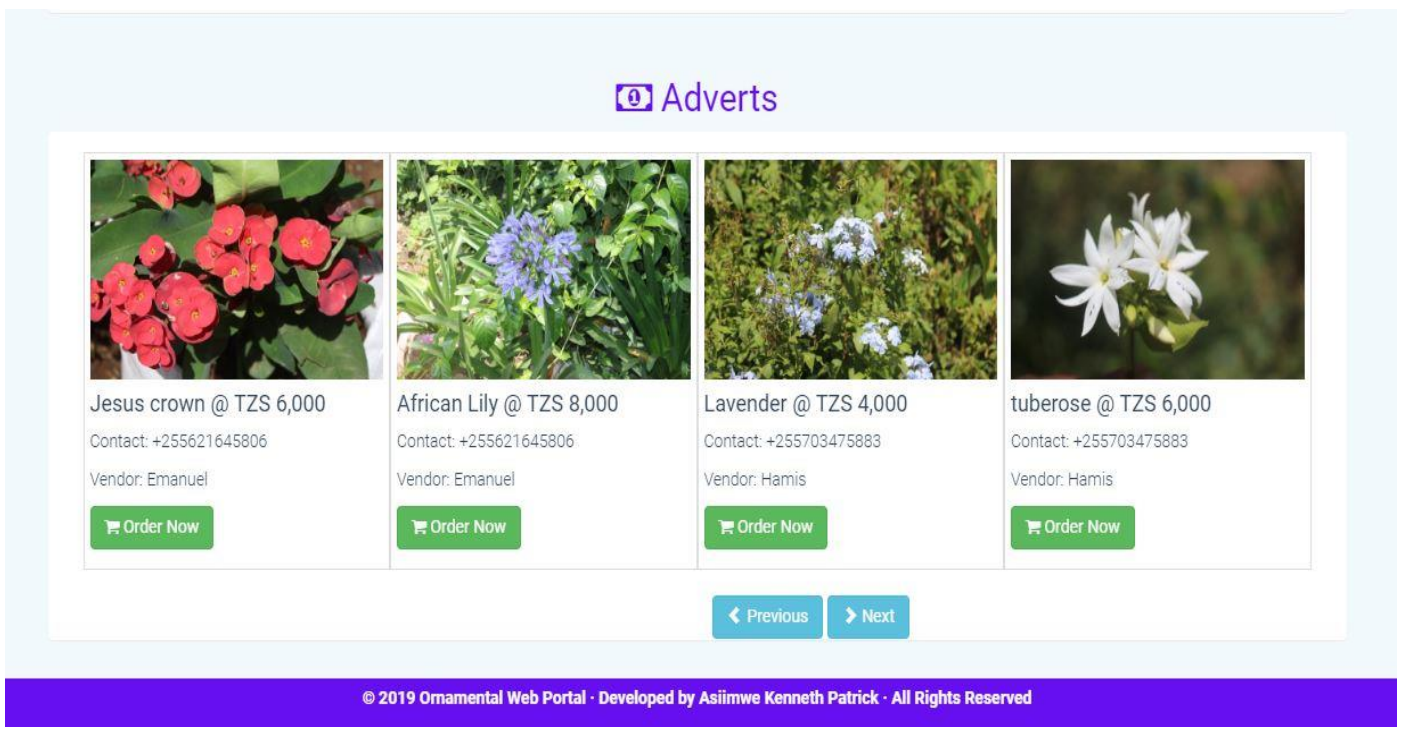

Fig.9. Web Page prototype Interface Showing vendors' approved adverts 
Furthermore, the ornamental web portal also has a visualization tool. Thus, Users of the system can select available categories from a drop down list provided at the visualization interface web page (as seen in Fig. 10) to perform visualization at the same time can save the charts as JPEG, PNG or even print. For example, the Fig. 10 below shows how a user can visualize data, details include; For example; user can select first category as Expensive plants and second category as Average prices and in this case the user can see each expensive plants with their average prices in the market by vendors in Arusha City. Among others are; Fast moving plants with average prices and in this case we meant the plants that vendors sell the most throughout the year and their average prices. Users can also visualize fast moving flowers with their average prices, users can also visualize sampled vendors by ward during data collection, showing the number of vendors that participated in this study and also users can visualize the vendors sampled by gender to see the demographic characteristics of the vendors in Arusha City and also visualize the level of education of vendors. This kind of visualization will be important for the Arusha City Representatives as they will have informed planning and decisions as far as Horticulture by vendors is concerned with Arusha district.

For the proposed system, various validation steps were chosen including; unit testing, integration testing, system testing, acceptance testing and regression testing to ensure that the user needs are met and satisfied. A total of 48 participants were involved in the exercise where by $95 \%$ agree that the portal is easy to use, agree to use it as a marketing platform, agree that it will help stake holders to view important information on the variety species of ornamental plants and flowers.

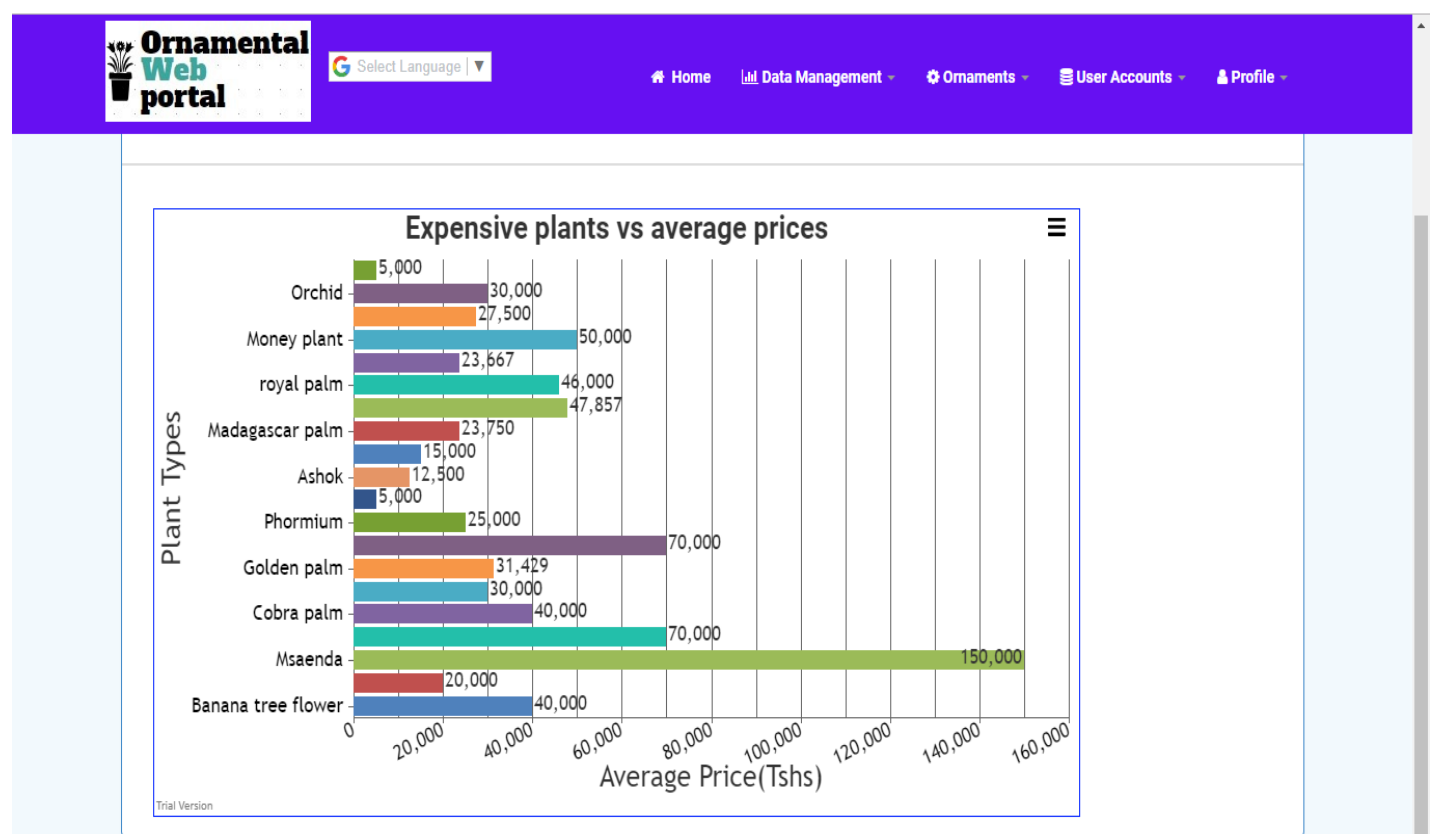

Fig.10. Web page prototype showing Visualization (one of the category) of ornamental plants with average prices

\section{CONCLUSION AND RECOMMENDATIONS}

The study delivered a solution by developing a web based interactive portal able to work together with a central database where this information on variety species of ornamental plants and flowers digitized and stored to be accessed by all stake holders freely online. In this system, the administrator can add information on ornamental plants and flowers, register vendors selling the ornamental plants and flowers together with the location of their businesses to be easily located by their customers. Additionally, the vendors can use the web portal as a marketing tool to connect to regional and international markets as they can advertise their product online. The study has also laid a foundation for the policy makers to be able access important information to make informed plans and decision that will develop the sector even more.

The future studies should extend further research to de- livery of other services in the horticulture sector such as using computer vision to identify the various species of ornamental plants and flowers automatically for industries such as the tourism industry, the scientific community and the general public. The research recommends the future studies to put emphasis on mobile application development for the vendors to improve usability and also consider an improved approach that involves both qualitative and quantitative methods in order for a more real description of the study and finding.

\section{ACKNOWLEDGEMENTS}

The authors would like to appreciate the African Development Bank (AFDB) for funding this study and The Nelson Mandela African Institution of Science and Technology for the tremendous support towards achievement of this study. Moreso all the participants that were involved in this study. 


\section{REFERENCES}

[1] N. and J. N. E. Neltnou-Nkoana, "The South African Frolicultural Industry and the Plant Breeders' Rights Act: A short Review," vol. 1976, no. 15, pp. 1-13, 2010.

[2] C. Donovan, "Agricultural Statistics in Sub-Saharan Africa: Differences in Institutional Arrangements and Their Impacts on Agricultural Statistics Systems . A Synthesis of Four Country Case Stud ... MSU INTERNATIONAL DEVELOPMENT WORKING PAPER Agricultural Statistics ,” no. January 2008, 2014.

[3] E. Fukase and W. Martin, "Agro-processing and horticultural exports from Africa," no. July, p. 59 pages, 2018.

[4] E. Jerusalem, "Agriculture in Sub-Saharan Africa : Prospects and challenges," vol. 181, no. November 1947, 2016.

[5] E. J. Mrema, A. V. Ngowi, S. S. Kishinhi, and S. H. Mamuya, "Pesticide Exposure and Health Problems Among Female Horticulture Workers in Tanzania," Environ. Health Insights, vol. 11, p. 117863021771523 , 2017.

[6] B. . D. Plant, "Tanzania Horticulture," 2015.

[7] M. M. Associates, "HORTICULTURE STUDY, Embassy of the kingdom of the netherlands," vol. I, no. March, pp. $1-50,2017$.

[8] HODECT, "Tanzania development strategy 2012-2021," p. 36, 2012.

[9] Embassy of the Kingdom of the Netherlands, "Mapping of production of fruits and Vegetables in Tanzania," 2017.

[10] K. Magwede, B. Van Wyk, and A. E. Van Wyk, "South African Journal of Botany An inventory of Vhaven d a useful plants," 2018.

[11] A. Hinsley et al., "A review of the trade in orchids and its implications for conservation," Bot. J. Linn. Soc., vol. 186, no. 4, pp. 435-455, 2018.

[12] S. O. and O. W. Suzanne Sharrock, "Plant conservation report 2014," no. 81, 2014.

[13] K. S. Negi, V. Tiwari, P. S. Mehta, and R. Rawat, "Botanical Identity of Seasonal Flowering Plants Available and Maintained in the Home Gardens of District Nainital , Uttarakhand," no. January, 2016.

[14] J. H. Park et al., "Floristic inventory of vascular plant in Nam Ha National Biodiversity Conservation Area, Lao People's Democratic Republic," J. Asia-Pacific Biodivers., vol. 11, no. 2, pp. 300-304, 2018.

[15] H. Benzeid et al., "Inventory of Toxic Plants in Morocco : An Overview of the Botanical , Biogeography , and Phytochemistry Studies," vol. 2018, pp. 1-14, 2018.

[16] Y. PLUGATAR, V. KOBA, and I. MITROFANOVA, "Inventory and Bioecological Assessment of Dendrologic Collection of Nikita Botanical Gardens," J. "Agriculture For., vol. 61, no. 4, 2015.

[17] S. B. Oswald Mashindano (PhD), Vivian Kazi, Specioza Mashauri, "Taping Export Opportunities for Horticulture Products in Tanzania: Do we have Supporting Policies and Institutional Frameworks ?," no. 2, pp. 1-4, 2013.

[18] Odi.org, "Case study : Arusha," 2017.

[19] L. Sherrell, "Evolutionary Prototyping," 2013.

[20] T. Crawford and T. Hussain, "A Comparison of Server Side Scripting Technologies," 2017.

[21] Malawi Data Portal, "Communication Statistics," Malawi Data Portal, no. March, 2016.

[22] R. Alfred and S. F. Kaijage, "Design of an Integrated Android Mobile Application and Web-Based System (IAMAWBS) as a Solution to Concerns of Passengers
Using Bus Rapid Transit System for Public Transportation in Dar Es Salaam," Int. J. Inf. Technol. Comput. Sci., vol. 11, no. 2, pp. 30-37, 2019.

[23] M. Dabbagh, S. P. Lee, and R. M. Parizi, "Functional and non-functional requirements prioritization: empirical evaluation of IPA, AHP-based, and HAM-based approaches," Soft Comput., vol. 20, no. 11, pp. 4497-4520, 2016.

\section{Authors' Profiles}

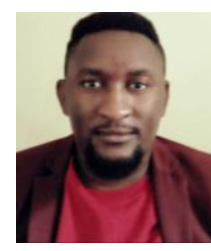

Kenneth P. Asiimwe is an IT expert, Consultant and researcher in the field of computer science specializing in software systems development, cyber security, data governance machine learning and business analytics (SEO expert). He received his BSc in Information Technology from Makerere University in Uganda, in 2017. Currently, he is a STEM ambassador of $\mathrm{MeCoPA}$ and a student at the Nelson Mandela African Institution of Science and Technology (NM-AIST) pursuing Master's Degree in Information and Communications Science and Engineering (ICSE)

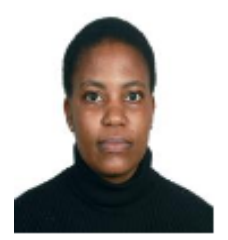

Dina Machuve is a Lecturer and researcher at the Nelson Mandela African Institution of Science and Technology (NM-AIST) in Tanzania. She holds a Ph.D. in Information and Communication Science and Engineering from Nm-AIST in 2016, MS in Electrical Engineering from Tennessee Technological University, USA in 2008, and BSc. in Electrical Engineering from the University of Dar es Salaam in 2001. Her research interests are Data Science, Bioinformatics, Agriculture Informatics on Food Value Chains and STEM Education in schools.

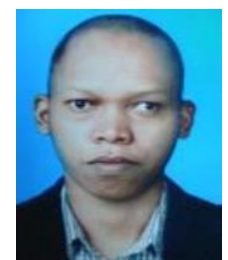

Mussa Ally Dida received his BSc in Computer Engineering and Information Technology from the University of Dar es Salaam and his MSc in Telecommunication Engineering from the University of Dodoma in 2008 and 2011 respectively, both in Tanzania. In 2017, he received his PhD in Information and Communication Engineering from Beijing Institute of Technology, in China. Currently he is working with the Nelson Mandela African Institute of Science and Technology (NM-AIST) in Arusha, Tanzania as a Lecturer. His research interests include digital signal processing, fractional Fourier transform signals and systems, physical layer security, and multiple input multiple output (MIMO) antennas.

How to cite this paper: Kenneth Patrick Asiimwe, Dina Machuve, Mussa Ally Dida, "A Web-based Portal for Ornamental Plants and Flowers in Arusha City, Tanzanian", International Journal of Information Technology and Computer Science(IJITCS), Vol.12, No.2, pp.32-41, 2020. DOI: $10.5815 /$ ijitcs.2020.02.04 